\title{
Corrigendum: Tumor-Associated Macrophages in Tumor Immunity
}

\section{OPEN ACCESS}

Approved by:

Frontiers Editorial Office,

Frontiers Media SA, Switzerland

*Correspondence:

Ting Zhang

zezht@zju.edu.cn

Xiaojian Wang

wangxiaojian@cad.zju.edu.cn

Specialty section:

This article was submitted to

Cancer Immunity

and Immunotherapy,

a section of the journal

Frontiers in Immunology

Received: 14 September 2021 Accepted: 02 November 2021

Published: 10 December 2021

Citation:

Pan $Y, Y u Y$, Wang $X$ and Zhang $T$ (2021) Corrigendum: Tumor-

Associated Macrophages

in Tumor Immunity.

Front. Immunol. 12:775758.

doi: 10.3389/fimmu.2021.775758
Yueyun Pan ${ }^{1,2}$, Yinda Yu $^{2}$, Xiaojian Wang ${ }^{2 *}$ and Ting Zhang ${ }^{1,2 *}$

1 Department of Radiation Oncology, Second Affiliated Hospital, School of Medicine, Zhejiang University, Hangzhou, Zhejiang, China, 2 Institute of Immunology, School of Medicine, Zhejiang University, Hangzhou, Zhejiang, China

Keywords: tumor-associated macrophages, regulation, immunosuppression, tumor microenvironment, tumor therapy

\section{A Corrigendum on}

Tumor-Associated Macrophages in Tumor Immunity

By Pan Y, Yu Y, Wang X and Zhang T (2020). Front. Immunol. 11:583084. doi: 10.3389/fimmu.2020.583084

The corresponding authors were incorrectly listed in the published work. In addition to Ting Zhang, author Xiaojian Wang is also a corresponding author.

The authors apologize for this error and state that this does not change the scientific conclusions of the article in any way. The original article has been updated.

Publisher's Note: All claims expressed in this article are solely those of the authors and do not necessarily represent those of their affiliated organizations, or those of the publisher, the editors and the reviewers. Any product that may be evaluated in this article, or claim that may be made by its manufacturer, is not guaranteed or endorsed by the publisher.

Copyright $\odot 2021$ Pan, Yu, Wang and Zhang. This is an open-access article distributed under the terms of the Creative Commons Attribution License (CC BY). The use, distribution or reproduction in other forums is permitted, provided the original author(s) and the copyright owner(s) are credited and that the original publication in this journal is cited, in accordance with accepted academic practice. No use, distribution or reproduction is permitted which does not comply with these terms. 